\title{
Ensino por Investigação em Ciências: Concepção e Prática na Educação não formal
}

\section{Teaching by investigation on Science: Conception and Practice on Non- formal education}

\author{
Daisy Flávia Souza Barbosa (daisyflavia@ig.com.br) \\ Universidade Federal do Pará (UFPA)
}

Joana Menezes Corrêa Monteiro (joiana.1@ hotmail.com)

Universidade Federal do Pará (UFPA)

João Manoel da Silva Malheiro (joaomalheiro@ufpa.br)

Universidade Federal do Pará (UFPA)

Marinalva Soares de Araújo (marisoares23004@gmail.com)

Universidade Federal do Pará (UFPA)

Resumo: Neste artigo objetivamos refletir sobre concepção e prática do ensino por investigação em Ciências, considerando sua manifestação na educação não formal. Para tanto, realizamos um estudo teórico sobre a temática com base nos registros de Sasseron (2015), Carvalho (2013), Carvalho et al. (2009), nos apoiando na Sequência de Ensino Investigativa proposta por estes últimos, como uma estratégia metodológica que valoriza na ação dos alunos: o levantamento de hipóteses, a busca pela resolução do problema e suas argumentações; comprometendo-se com o processo de (re)construção do conhecimento. Além destes, consideramos uma Atividade Experimental Investigativa denominada "O regador econômico", realizada num Clube de Ciências, a qual fortalece a importância de ultrapassar as formas de ensino que valoriza a simples manipulação de materiais, impulsionando a ideia de que o saber fazer precisa estar acompanhado do compreender. Desta forma, concluímos que a prática neste espaço de educação não formal, confirma que o ensino por investigação, também, é possível de ser concretizado fora dos espaços escolares, tendo em vista a aprendizagem baseada na autonomia do aluno.

Palavras-Chave: Ciências; Ensino por investigação; Educação não formal.

Abstract: In this article, we aim to reflect on the conception and practice of teaching by research in science, considering its manifestation in non-formal education. For that we management a theoretical study on the theme, based on the records of Sasseron (2015), Carvalho (2013) Carvalho et al. (2009). Supporting us in the Investigative Teach Sequence, proposed by the latter, as a methodological strategy that values students' actions, the raising of hypotheses, a search for problem solving and their arguments; committing to the knowledge (re) construction process. In addition, we consider an Experimental Investigative Activity called "The economic regulator", realized at the 
Science Club, which strengthens the importance of overcoming the forms of teaching that value simple handling of materials; boost the idea that knowing how to do must be accompanied by understanding. In this way, we believe that practice, in this non-formal education space, confirms research teaching it is also possible to be implemented in school spaces, with a view to learning, based on the student's capacity.

Keywords: Sciences; Teaching by investigation; Non-formal education.

\section{INTRODUÇÃO}

Durante muitos anos o ensino das ciências esteve centrado na memorização de conteúdos, na realização de atividades de mecanização e na aplicação de regras à resolução de questões semelhantes às apresentadas e resolvidas pelo professor (COSTA, 1999). Esta visão mecanicista entendia as ciências como um corpo organizado de conhecimentos e regras a aprender e a aplicar sem qualquer ligação com a realidade.

Considerando as diversidades de saberes, o sistema educacional passou assumir novas tendências comprometidas com a diversidade de opiniões, a fim de transformar a realidade com base em projeções futuras.

Morin (2002) nos fala desse desafio da educação que se volta para o futuro, como uma complexidade de ações que inclui o diálogo, o próprio contexto em que ela se realiza e a incerteza como abertura epistemológica para o conhecer.

Vale ressaltar que, essa abertura é importante e torna-se necessária à ação educativa, uma vez que colabora no sentido de considerar o aluno participante nas tomadas de decisões; e os professores como mediadores do processo. Em síntese, isso implica repensar o processo de ensino e aprendizagem, desenvolvendo uma proposta em que os alunos possam adquirir estratégias e habilidades que fortaleçam a formação de um pensamento autônomo, crítico e reflexivo (LIBÂNEO, 2001).

Desta forma, é importante salientar o valor do ensino por investigação em ciências, que é uma abordagem didática que valoriza as atividades centradas no aluno, possibilitando o desenvolvimento da autonomia e da capacidade de tomar decisões, de avaliar e de resolver problemas (SASSERON, 2015), podendo ser aplicado em espaços de educação formal e/ou não formal. 
Considerando o exposto, estabelecemos para este estudo a seguinte questão problema: de que maneira o ensino por investigação pode ser organizado em espaço não formal, como um Clube de Ciências? Para responder tal questionamento, propõe-se refletir sobre concepção e prática desta abordagem didática, tendo em vista uma Sequência de Ensino Investigativa.

Diante disso, organizamos este texto em três seções. Na primeira, intitulada ensino por investigação em ciências, apresenta-se suas concepções gerais, enfatizando a Sequência de Ensino Investigativa, proposta por Carvalho et al. (2009). Na segunda, é realizada uma conexão entre a educação não formal e o ensino investigativo, ressaltando a proposta pedagógica do Clube de Ciências Prof. Dr. Cristovam W. P. Diniz. E na terceira, registra-se a atividade experimental investigativa: "O regador econômico", desenvolvida no Clube de Ciências, visando destacar, com base na prática, uma estratégia metodológica de ensino por investigação.

\section{ENSINO POR INVESTIGAÇÃO EM CIÊNCIAS}

O ensino por investigação é apontado por Sasseron (2015) como uma abordagem didática, podendo assumir diversas estratégias, inovadoras ou não, desde que considere o aluno como sujeito ativo, não cabendo a ele apenas ouvir e copiar propostas pré- definidas.

Neste sentido, o papel do professor e do aluno deixa de ser o de transmitir e receber o conhecimento, respectivamente, uma vez que o pressuposto básico do ensino por investigação é o "estabelecimento de um ambiente propício a discussões e a apresentação de ideias, ainda que elas possam parecer divergentes" (SASSERON, 2015, p.122).

Assim, o posicionamento e a expressão de pensamentos precisam ser incentivados pela ação docente, o qual deve estar apto a fazer perguntas e a ouvir as respostas, assumindo um papel de orientador, considerando os alunos como atores centrais de suas aprendizagens. Neste sentido, a problematização ganha força nas atividades propostas, tendo em vista a construção do conhecimento com motivação nos problemas.

De acordo com Krulik e Reys (1997, p. 131), “um problema é uma situação, quantitativa ou não, que pede uma solução para o qual os indivíduos implicados não conhecem meios ou caminhos evidentes para obtê-la". Para tanto, não está relacionado 
com a busca de uma única resposta, mas com o surgimento de diversas formas de resolução e, consequentemente, diferentes resultados alcançados.

Para Carvalho et al. (2009, p.20), “o problema é a mola propulsora das variadas ações dos alunos: ele motiva, desafia, desperta o interesse e gera discussões", sendo, portanto, o elemento promotor da investigação. Entretanto, não deve ser um problema qualquer, "deve estar dentro da cultura dos alunos, sendo interessante para eles, de tal modo, que se envolvam na busca de uma solução e permita que exponham seus conhecimentos espontâneos sobre o assunto" (CARVALHO, 2013, p.6).

O problema e as experiências espontâneas dos alunos, no entanto, devem dar condições para que construam suas hipóteses e possam testá-las procurando resolver a proposta, a fim de refutar os obstáculos já acumulados pela vida cotidiana.

De acordo com Carvalho (2013), a derrubada destes obstáculos não é uma tarefa fácil; e um caminho é aceitar a proposta de Bachelard e procurar mudar a cultura experimental - da espontânea à científica, visando o desenvolvimento da aprendizagem.

Para Bachelard (1996, p.18) "todo conhecimento é resposta a uma pergunta. Se não há pergunta não há conhecimento científico. Nada é evidente. Nada é gratuito. Tudo é construído". Assim, as atividades a serem desenvolvidas devem ultrapassar as ações manipulativas, contemplando, também, a construção abstrata do conhecimento.

Desta forma, a conclusão de uma atividade não se limita a resolução do problema. É necessária, além do saber fazer, a busca pela compreensão daquilo que se faz. Vale destacar que o saber fazer é somente utilizar as coisas com sucesso, enquanto que o compreender é conseguir dominar, em pensamento; é isolar a razão das coisas (CARVALHO et al., 2009). Assim, há uma passagem da ação manipulativa a ação intelectual, tendo em vista a tomada de consciência e a construção de explicações sobre problema investigado.

Diante do exposto, consideramos que o ensino por investigação exige a organização de diferentes momentos pedagógicos, a fim de contemplar a ação e a reflexão sobre a ação, de forma a favorecer a compreensão do objeto investigado. 
Considerando a proposta de Carvalho et al. (2009), são sete as principais etapas, descritas no quadro 1, que fundamentam a apresentação de uma proposta investigativa, a qual denomina de Sequência de Ensino Investigativa (SEI).

Quadro 1 - Etapas da SEI

\begin{tabular}{|c|c|}
\hline Etapas & Descrição \\
\hline $\begin{array}{l}\text { 1. O professor propõe o } \\
\text { problema }\end{array}$ & $\begin{array}{l}\text { O professor divide a turma em grupos de no máximo cinco } \\
\text { alunos. Após, faz o questionamento inicial, dando a } \\
\text { oportunidade para que o aluno chegue à solução. Em } \\
\text { seguida, ocorre a distribuição dos materiais. É importante } \\
\text { salientar que em nenhum momento o professor pode dar } \\
\text { respostas prontas. Seu propósito é de estimular os alunos a } \\
\text { pensarem em novas hipóteses para a resolução do problema. }\end{array}$ \\
\hline $\begin{array}{l}\text { 2. Agindo sobre os objetos } \\
\text { para ver como eles reagem }\end{array}$ & $\begin{array}{l}\text { Para resolver o questionamento proposto na etapa anterior, } \\
\text { os alunos iniciam o processo de descoberta manuseando o } \\
\text { material experimental. Neste momento, os professores } \\
\text { passam nos grupos para verificarem se os alunos entenderam } \\
\text { o problema e se todos estão tendo oportunidade de } \\
\text { manipular os objetos. }\end{array}$ \\
\hline $\begin{array}{l}\text { 3. Agindo sobre os objetos } \\
\text { para obter o efeito desejado }\end{array}$ & $\begin{array}{l}\text { Após se familiarizarem com materiais dispostos, os alunos } \\
\text { passam a agir sobre eles para obterem o efeito que } \\
\text { corresponde à solução do problema. Neste momento, os } \\
\text { professores pedem nos grupos para mostrarem e falarem } \\
\text { sobre o que estão fazendo. }\end{array}$ \\
\hline $\begin{array}{l}\text { 4. Tomando consciência de } \\
\text { como foi produzido o efeito } \\
\text { desejado }\end{array}$ & $\begin{array}{l}\text { Terminada a solução do problema, os alunos formam um só } \\
\text { grupo para dialogarem sobre o que foi feito no decorrer do } \\
\text { processo. Neste momento o material é recolhido, a fim de } \\
\text { que a atenção seja voltada para a discussão em grupo, sendo } \\
\text { então, o momento de pensar e falar sobre as descobertas. } \\
\text { Para iniciar a socialização, o professor pede aos alunos que } \\
\text { relatem como chegaram à resolução do problema. }\end{array}$ \\
\hline $\begin{array}{l}\text { 5. Dando explicações } \\
\text { causais }\end{array}$ & $\begin{array}{l}\text { Neste momento, os alunos são estimulados a responderem } \\
\text { questionamentos (por quê?), mas nem sempre se obtêm de } \\
\text { imediato uma explicação. Com novos questionamentos } \\
\text { (envolvendo o porquê) são estimulados a explicarem o } \\
\text { motivo de o experimento ter dado certo. }\end{array}$ \\
\hline 6. Escrevendo e desenhando & $\begin{array}{l}\text { É a etapa em que o professor solicita aos alunos que } \\
\text { escrevam e desenhem sobre a atividade experimental. Neste } \\
\text { momento, o aluno fica livre para realizar de forma criativa a } \\
\text { proposta, valorizando a sistematização individual do } \\
\text { conhecimento. }\end{array}$ \\
\hline $\begin{array}{l}\text { 7. Relacionando atividade e } \\
\text { cotidiano }\end{array}$ & $\begin{array}{l}\text { O aluno é estimulado a relacionar a atividade e o cotidiano. } \\
\text { Assim, o professor incentiva os alunos a darem o maior } \\
\text { número de exemplos, valorizando a diversidade de } \\
\text { experiências que cada um traz. }\end{array}$ \\
\hline
\end{tabular}

Fonte: Carvalho et al. (2009). Adaptado

Vale ressaltar que em alguns momentos essas etapas acontecem de forma simultânea, mas é importante que o professor compreenda cada uma delas, para saber o seu papel em todo o processo da SEI. Neste contexto, uma das metas do ensino é 
desenvolver alunos autônomos, que saibam tomar suas próprias decisões, dando sentido e controle na realização do seu trabalho.

A cooperação entre os sujeitos envolvidos, também, é valorizada numa perspectiva motivada pelo diálogo. De acordo com Carvalho et al. (2009, p.31) "quando se aumentam as oportunidades de discussão e de argumentação, consequentemente se incrementa a habilidade dos alunos de compreender os temas ensinados e o processo de raciocínio envolvido".

O erro, por sua vez, é transformado em situações de aprendizagem, sendo essencial na ação educativa (CARVALHO et al., 2009), pois os alunos, ao buscar respostas às suas dúvidas, apresentam uma liberdade intelectual favorável para a construção de conceitos. Neste processo, a avaliação da aprendizagem ganha força na concepção mediadora, servindo para encorajar e reorganizar o saber, num permanente vir a ser; não se tratando aqui "de não delinearmos pontos de partida, mas, sim, de não delimitarmos ou padronizarmos pontos de chegada." (HOFMANN, 2009, p. 32).

Nesta abordagem a relação professor-aluno não se dá por meio da transmissão e recepção de saberes, mas busca valorizar a interação e a troca de informações, a serem transformadas em conhecimento. Desta forma, "espera-se de um professor muito mais do que saber expor a matéria e ter bom relacionamento com os alunos. É necessário que suas aulas sejam criativas e que nelas haja espaço para que surjam novas situações de aprendizagens" (CARVALHO et al., 2009).

Diante do exposto, abordar as ciências, considerando o ensino por investigação, requer um trabalho que valorize a autonomia do aluno, tendo como foco as tomadas de decisões e resoluções dos problemas em prol da (re) construção do conhecimento.

\section{EDUCAÇÃO NÃO FORMAL E O ENSINO INVESTIGATIVO}

As questões que envolvem o ensino não estão somente relacionadas às metodologias ou práticas pedagógicas. É preciso, também, pensar os espaços em que elas ocorrem, as interações entre os sujeitos e sua lógica de funcionamento. 
A maioria dos questionamentos em relação a essa visão de educação é centrada nos espaços de educação formal. Compartilhando do pensamento de Moura e Zucchetti (2010) há a necessidade de perceber a educação na construção de significados e os espaços em que estes podem ser compartilhados. Também, como sinaliza Freire (1987) a educação está associada a um contexto social e as ações dos sujeitos.

Para Dias (2007), o modelo que vivenciamos nas escolas tem trazido dificuldades às práticas mais emancipatórias; acredita-se que para o êxito do processo educativo, a alternativa possa ser a educação não formal. Isso porque, em função da sua flexibilidade de tempo e de conteúdo, ela pode levar ao desenvolvimento de uma educação mais direcionada aos interesses de setores sociais (DIAS, 2007). Vale ressaltar que esta situação não exige que seja feita uma substituição de um modelo por outro, mas a compreensão desses espaços e como suas práticas se constituem.

De acordo com Libâneo (1998), há a necessidade de aceitar que a escola não é mais o único local da educação, pois esse processo pode ocorrer através dos meios de comunicações, pelas empresas e/ou Clubes de ciências, por exemplo. Porém, é preciso entender como se constituem essas formas e esses espaços educativos.

Marques e Freitas (2017) mostram por meio de sua pesquisa algumas dimensões, explicitadas no quadro 2, em que é possível estabelecer critérios para diferenciar e reconhecer a educação, seja ela: formal, não formal ou informal.

Quadro 2. Dimensões para diferenciar a educação formal, não formal e informal.

\begin{tabular}{|c|l|}
\hline Dimensões & \multicolumn{1}{|c|}{ Características } \\
\hline Processos & $\begin{array}{l}\text { Compreendem as relações entre professor-aluno, atividade individual } \\
\text { e coletiva, avaliação, abordagem pedagógica, mediação da } \\
\text { aprendizagem, aprendizagem tácita ou explícita, aprendizagem } \\
\text { contextual ou generalizada o papel das emoções na aprendizagem. }\end{array}$ \\
\hline Conteúdo & $\begin{array}{l}\text { Compreende a natureza e os tipos de conhecimentos e o estatuto desse } \\
\text { conhecimento. }\end{array}$ \\
\hline Estrutura & $\begin{array}{l}\text { Compreende a localização, grau de planejamento e estrutura, } \\
\text { determinação de objetivos e resultados, duração e tempos de } \\
\text { aprendizagem, tipos de grupos e certificação. }\end{array}$ \\
\hline Propósitos & $\begin{array}{l}\text { Compreende os aspectos relacionados à intencionalidade do } \\
\text { professore aluno, interesses endereçados e objetivos de aprendizagem. }\end{array}$ \\
\hline
\end{tabular}

Fonte: Marques e Freitas (2017). Adaptado

Diante do exposto e como especificidade deste estudo, é possível definir algumas características da educação não formal. Gohn (2006) ressalta que ela se desenvolve por 
meio de processos interativos e fora da escola, também é marcada por uma intencionalidade e por uma construção coletiva, que a faz seguir as diretrizes de um grupo em que seus sujeitos estão associados, e estes mostram uma participação mais ativa nas atividades.

Existem alguns espaços característicos para essa forma de educação. Marandino et al. (2004) os definem como culturais ou interativos, e que em cada um deles, a aprendizagem está associada as práticas sociais de interesse dos seus membros. Por terem como objetivo, atender um público específico, cada espaço tem o seu planejamento todo direcionado e desenhado para o interesse de aprendizagem desse grupo (SILVA; BASTOS; SILVA, 2017).

A aprendizagem, nesses espaços, depende de um contexto particular e das interações. Gohn (2014) explica que a aprendizagem se vincula a produção de saberes e que é marcada por condicionalidades do espaço em que estão inseridos os indivíduos, por isso, os conteúdos aprendidos têm relação com as suas experiências sociais. O fato de não terem um currículo guiando o que deve ser desenvolvido e quais temas trabalhar, faz com que essa forma de educação atue numa outra perspectiva e com maior liberdade (GOHN, 2014).

Nesses lugares os alunos são oportunizados com práticas diferentes do ambiente escolar, com dados e materiais que eles podem manipular, o que os tornam mais ativos na construção da aprendizagem. Foi o que demonstrou o trabalho de Alves et al. (2020) em um museu de solo, onde foram desenvolvidas atividades de Geografia e Ciências, as quais possibilitaram que as aulas se tornassem mais atrativas e diferentes das realizadas na escola. De acordo com os autores, tais práticas promoveram mais conhecimento aos sujeitos envolvidos.

Para Castro (2015), tanto a educação formal quanto a não formal atuam compartilhando dos mesmos processos e propósitos, que são a formação humana e as transformações sociais. Desse modo, discute a necessidade de pensar essas formas como integradas, bem como a importância desses espaços, de seus conteúdos e metodologias.

Como exemplo de grupos e de espaços em que a educação não formal pode ser desenvolvida, temos os clubes de ciências. Schmitz e Tomio (2019) explicam que estes 
são ambientes de aprendizagens e seus integrantes se associam porque têm interesses comuns; as atividades desenvolvidas têm duração de acordo com o que é estabelecido pelo grupo e há compartilhamentos de saberes entre seus membros.

O sucesso dos clubes de ciências está relacionado à forma como são conduzidas as práticas e como se objetiva a construção do conhecimento. Para Lopes e Scheifele (2016), nestes espaços, os alunos se sentem mais livres nos processos de tomadas de decisões, o que é revelado no seu envolvimento e protagonismo nas atividades. Além disso, por meio do aprender a fazer, eles desenvolvem ativamente a capacidade de análise e reflexão crítica-investigativa (LOPES; SCHEIFELE, 2016).

A maioria dos trabalhos realizados, nesses espaços, parte de uma metodologia de ensino investigativo. Para Batista e Silva (2018), apesar desse ensino ter passado por transformações nos últimos anos, as atividades realizadas por meio dele têm em comum o fazer científico, o uso da linguagem científica e a capacidade argumentativa dos alunos. É possível estabelecer e reconhecer para este ensino, processos e propósitos comuns, conforme quadro 3:

Quadro 3: Características do ensino investigativo

- Construção de um problema e sua introdução para os alunos.

- Criação de hipóteses, ideias, debates, reflexões e argumentações entre os alunos.

- Valorização das observações feitas pelos alunos sobre o problema/fenômeno/situação.

- Experimentação e avaliação dos dados em busca de resultados.

- Aplicação do conhecimento prévio sobre o problema, conduzida pela orientação do professor.

- Confrontação das expectativas iniciais do problema para obtenção de uma resposta.

- Discussão sobre os relatos da resposta final envolvendo alunos e professores, para uma finalização do problema.

Fonte: Batista e Silva (2018). Adaptado.

A partir das características listadas acima, pode-se definir que os pontos comuns para o ensino investigativo têm relação com os problemas direcionados aos alunos, as hipóteses que eles constroem e as soluções para a situação colocada; além do próprio diálogo interativo entre eles que permite a trocas de ideias.

Essa mesma perspectiva de trabalho investigativo encontramos no espaço do Clube de Ciências Prof. Dr. Cristovam W. P. Diniz. Rocha e Malheiro (2018) definem-no como um ambiente de iniciação científica e de formação de professores na área de Ciências e 
Matemática. Ele funciona também como espaço para a pesquisa, além das interações de alunos e professores, por meio de suas atividades práticas investigativas.

Sua metodologia é pautada na SEI, proposta por Carvalho et al. (2009), mencionada na seção anterior deste estudo. São várias as Atividades Experimentais Investigativas (AEI), criadas e desenvolvidas para as interações com os alunos, dentre elas: "O regador econômico", abordada a seguir.

Além disso, o Clube de Ciências, em questão, realiza por meio dessa proposta, as atividades práticas que desenvolvem uma aprendizagem focada em atitudes, processos e conceitos. De acordo com Júnior e Coelho (2015), essas dimensões podem ser identificadas em metodologias investigativas. Desse modo, a dimensão atitudinal pode ser verificada quando os alunos criam hipóteses ou passam a considerar a visão do outro; a conceitual representa a retomada de aprendizagens; e a procedimental é a manipulação do experimento para testar as hipóteses (JÚNIOR; COELHO, 2015).

Vale ressaltar que tal espaço de educação não formal, ao focar seu trabalho no ensino investigativo, vai ao encontro dos objetivos deste, que não está associado apenas ao conhecimento científico, mas nos processos educativos que ele pode proporcionar. Assim, destacamos que quando os alunos realizam a experimentação por meio do problema que foi colocado, o mais importante na atividade é "o questionamento, a curiosidade, o desejo de procurar respostas através de sua investigação própria e os intercâmbios entre os colegas" (ASTOLFI; DEVELAY, 2012, p. 72).

Desta forma, há uma valorização das falas dos alunos em seus questionamentos e elaboração das hipóteses para o trabalho. Além disso, por meio de suas atividades, tem-se como objetivo construir aprendizagens relacionadas ao contexto dos alunos.

De acordo com Zompero, Figueiredo e Garbim (2017), quando se trabalha as atividades investigativas direcionadas a questões das experiências dos alunos, há maior possibilidade de transferência de conhecimentos científicos para os seus contextos, o que promove uma aprendizagem mais significativa e mudanças de hábitos. 


\section{ATIVIDADE EXPERIMENTAL INVESTIGATIVA NO CLUBE DE CIÊNCIAS PROF. DR. CRISTOVAM W. P. DINIZ}

A Atividade Experimental Investigativa (AEI) escolhida para fundamentar este estudo foi "O regador econômico", realizada no Clube de Ciências Prof. Dr. Cristovam W. P. Diniz, a qual teve como objetivo trabalhar na forma de SEI, conteúdos conceituais, procedimentais e atitudinais, envolvendo temas como: água, meio ambiente e pressão atmosférica. A mesma foi realizada em três sábados consecutivos, como podemos observar no Quadro 4:

Quadro 4: SEI - O regador econômico

\begin{tabular}{|c|c|c|}
\hline Dia & Etapas da SEI & Desenvolvimento da SEI \\
\hline & $\begin{array}{l}\text { 1. O professor propõe o } \\
\text { problema. }\end{array}$ & $\begin{array}{l}\text { Alunos organizados em semicírculos. O professor } \\
\text { propôs o problema: Como fazer um regador } \\
\text { econômico, utilizando garrafa pet? }\end{array}$ \\
\hline & $\begin{array}{l}\text { 2. Agindo sobre os objetos } \\
\text { para ver como eles reagem }\end{array}$ & $\begin{array}{l}\text { Os alunos, divididos em quatro equipes, } \\
\text { manipularam os materiais a fim de familiarizarem- } \\
\text { se com os mesmos. Enquanto isso, os professores } \\
\text { monitores observavam se eles compreenderam o } \\
\text { problema. }\end{array}$ \\
\hline $\mathbf{1}^{\mathbf{o}}$ & $\begin{array}{l}\text { 3. Agindo sobre os objetos } \\
\text { para obter o efeito } \\
\text { desejado }\end{array}$ & $\begin{array}{l}\text { Verificado que as equipes compreenderam o } \\
\text { problema, os alunos ficaram livres para que, em } \\
\text { conjunto, tentassem solucionar o problema } \\
\text { proposto. Durante esse momento, os professores } \\
\text { monitores acompanhavam as ações do grupo. }\end{array}$ \\
\hline$a$ & $\begin{array}{l}\text { 4. Tomando consciência de } \\
\text { como foi produzido o } \\
\text { i efeito desejado. }\end{array}$ & $\begin{array}{l}\text { Um dos professores abriu as discussões, } \\
\text { convidando os alunos para exporem o percurso } \\
\text { realizado no processo de resolução do problema. }\end{array}$ \\
\hline & $\begin{array}{l}\text { 5. Dando explicações } \\
\text { causais }\end{array}$ & $\begin{array}{l}\text { Ao se constatar que todos, ou a maioria dos alunos, } \\
\text { apresentaram suas ideias, os professores } \\
\text { indagaram sobre o porquê de a atividade ter dado } \\
\text { certo ou não. Valorizou-se o posicionamento de } \\
\text { todos, com intervenções necessárias. }\end{array}$ \\
\hline $2^{\circ}$ & $\begin{array}{l}\text { 6. Relacionando atividade } \\
\text { e cotidiano }\end{array}$ & $\begin{array}{l}\text { Nesta etapa foram exibidos vídeos relacionados a } \\
\text { atmosfera e pressão atmosférica. Além disso, } \\
\text { houve a confecção de vasos em formato de } \\
\text { bicicleta para o plantio de mudas. }\end{array}$ \\
\hline $3^{\mathbf{o}}$ & $\begin{array}{l}\text { 7. Escrevendo e } \\
\text { desenhando }\end{array}$ & $\begin{array}{l}\text { Neste momento, houve a produção de cartas } \\
\text { direcionadas ao coordenador do Clube de Ciências. }\end{array}$ \\
\hline
\end{tabular}

Fonte: Acervo dos autores (2018)

De acordo com o exposto, as etapas de 1 a 5 foram concretizadas no primeiro sábado; a etapa 6, no segundo; e a etapa 7, no terceiro. Assim, pode-se constatar que a SEI foi planejada de acordo com a proposta de Carvalho et al. (2009), descrita no quadro 1; 
havendo uma inversão na ordem das etapas 6 e 7, pois acreditou-se que o escrever e desenhar representa um instrumento de avaliação individual dos conceitos construídos em todo o processo, incluindo a aproximação com a realidade.

Além das etapas acima, nesta proposta foram desenvolvidas outras atividades consideradas complementares, observadas a seguir.

No primeiro sábado foi realizada a elaboração dos acordos de convivência (atividade complementar 1), na qual os alunos elencaram algumas atitudes necessárias para o sucesso da atividade investigativa. Os acordos foram organizados em cartazes com formato de flores e lidos em voz alta pela professora-monitora ${ }^{1}$ que conduzia esse momento.

Em seguida, deu-se início a dinâmica "A reunião das flores"² (atividade complementar 2) que tinha por objetivo formar 4 grupos de trabalhos, tendo dois professores-monitores como responsáveis por cada um. Ao término desta, houve um momento de reflexão sobre a importância de regar as plantas no dia-a-dia, tendo em vista a economia de água e o comprometimento com a preservação do meio ambiente.

Partiu-se daí a proposição do problema (etapa 1): “Como fazer um regador econômico, utilizando garrafa pet?" Destacamos, aqui, a importância da pergunta inicial, para o processo de aprendizagem, enfatizando a ideia de que todo conhecimento é resposta a uma pergunta (BACHELARD, 1996).

Com o problema proposto, houve a apresentação dos materiais ${ }^{3}$ que seriam usados na SEI. Os alunos manusearam cada item, enquanto os professores-monitores observavam se todos haviam compreendido o problema e se cada componente do grupo estava conseguindo tocar nos materiais para ver como eles reagiam (etapa 2). Observado a dificuldade dos alunos, os professores-monitores fizeram a retomada do problema, a fim de fornecer aos grupos a compreensão da função de cada material distribuído. De acordo com Carvalho et al. (2009), estas orientações são muito importantes, pois redimensionam as tomadas de decisões dos alunos, criando condições para que refaçam mentalmente suas ações e as verbalizem.

\footnotetext{
${ }^{1}$ Nomenclatura utilizada para se referir aos orientadores das atividades desenvolvidas no Clube de Ciências. Ressaltamos que nesta SEI havia 8 professores-monitores para 25 alunos.

${ }^{2}$ Disponível em: http://ivoneifrr.blogspot.com/2010/11/dinamica-de-grupo-reuniao-das-flores.html

3 Materiais: garrafa pet, furador confeccionado com prego, balde com água, copo descartável e bandeja plástica.
}

Recebido em: 26/05/2020 
Compreendido o problema, deu-se início a etapa 3, onde as equipes testaram suas hipóteses iniciais, sendo que não conseguiram de imediato chegar a uma solução. Os professores-monitores, então, realizaram intervenções por meio de perguntas relacionadas à estrutura e função de um regador, contribuindo para que os grupos percebessem seus erros e elaborassem novas hipóteses. Neste momento, o erro não é compreendido como um problema, podendo ser transformado em novas situações de aprendizagens, sendo um instrumento importante "para separar as variáveis que interferem, daquelas que não interferem na resolução do problema" (CARVALHO, 2013, p.12)

Aos poucos, os grupos conseguiram resolver o problema, percebendo que ao tampar uma garrafa furada, era possível reter água no seu interior; e ao destampá-la, acontecia o vazamento. Esta situação se explica pela ação da pressão atmosférica ${ }^{4}$, sendo este conceito construído pelos alunos no decorrer da sequência, num movimento de superação dos conhecimentos espontâneos ao científico.

É importante ressaltar que, durante toda a etapa que visou obter o efeito desejado construção do regador econômico - muitas orientações por parte professores-monitores ocorreram, as quais favoreceram o levantamento de novas hipóteses, os debates e a argumentação. Neste contexto, destacamos que "o importante não é o conceito que se quer ensinar, mas as ações manipulativas que dão condições aos alunos levantar hipóteses e os testes delas". (CARVALHO, 2013, p.11)

Com o problema solucionado, houve a tomada de consciência do efeito desejado (etapa 4). A princípio, foram recolhidos os materiais e os alunos organizados em semicírculo. O professor-monitor perguntou como as equipes fizeram para solucionar o problema, convidando os grupos a exporem suas aprendizagens. Após, a explanação dos grupos, iniciou-se as explicações causais (etapa 5), onde foi solicitado aos alunos que explicassem o porquê de o experimento ter dado certo. De acordo com Carvalho (2009) é durante estas etapas que os alunos têm a oportunidade de construir sua compreensão dos fenômenos estudados. Assim, reforçamos a importância do fazer acompanhado do compreender nos processos de (re) construção do conhecimento.

\footnotetext{
${ }^{4}$ A pressão atmosférica que age em todas as direções aplica uma força através dos furos da garrafa, contendo a água dentro, quando esta está fechada. Ao destampá-la ocorre o vazamento, pois a pressão atmosférica, somada à hidrostática, torna a pressão interna maior que a externa.
}

Recebido em: 26/05/2020 
O segundo sábado iniciou-se com a retomada das etapas realizadas anteriormente, onde uma equipe refez o experimento do regador econômico. Ao término da demonstração, houve o momento de relacionar a atividade com o cotidiano (etapa 6), a partir da utilização de vídeos que retratavam conceitos como: atmosfera, pressão atmosférica, meio ambiente e consumo consciente de água. Por fim, os alunos produziram a bicicleta/vaso, seguido pelo plantio de mudas (atividade complementar 3), para que, posteriormente, pudessem utilizar o regador.

Assim, houve uma valorização da construção do conhecimento por meio da criação de novos significados para (re) pensar a relação homem e meio ambiente, considerando que "as atividades experimentais permitem ultrapassar a simples manipulação de materiais" (CARVALHO et al., 2009, p.44)

O terceiro sábado, por sua vez, teve seu início com a síntese de acontecimentos dos encontros anteriores. Na sequência, foi proposta a elaboração de uma carta ao coordenador do Clube, onde os alunos deveriam contar o que haviam aprendido com a Atividade Experimental Investigativa. Cada um escreveu e desenhou (etapa 7), sendo este momento considerado um "instrumento de aprendizagem que realça a construção do conhecimento" (CARVALHO, et al., 2013, p.13).

Ao término desta, foi realizada a caça ao tesouro (atividade complementar 4), com perguntas relacionadas às atividades desenvolvidas nos sábados anteriores, caracterizada como outra ferramenta avaliativa, fortalecida pelo lúdico. Neste momento, é importante salientar que durante todo o processo, procurou-se concretizar uma avaliação numa perspectiva mediadora, conforme mencionado na primeira seção.

\section{CONSIDERAÇÕES FINAIS}

Diante da questão levantada para este estudo, foi possível constatar que o ensino em espaço de educação não formal, como clube de ciências, pode se organizar de forma a fortalecer uma educação onde o aluno é visto como um sujeito que (re) constrói o conhecimento, por meio da investigação. Desta forma, é norteado por metodologias que questionam a transmissão e assimilação do saber e se fortalecem em propostas que valorizam o diálogo, a compreensão e a criação de novos significados. Neste sentido, as 
atividades experimentais em ciências, pretendem ultrapassar a simples manipulação de materiais, por meio da demonstração; caminhando para a reflexão e a busca de explicações dos fenômenos estudados.

Na prática, esse processo se dá, por exemplo, a partir de uma Sequência de Ensino Investigativa (SEI), adotada na proposta de trabalho do Clube de Ciências que fundamentou este estudo. Neste, identificamos por meio da Atividade: "O regador econômico"; que o saber fazer precisa estar acompanhado do compreender, dentro de um processo de resolução do problema, além da sistematização coletiva e individual do conhecimento. Assim, afirmamos que, na educação não formal, o ensino por investigação também é possível; confirmando-se como mais um espaço que promove a aprendizagem com base na autonomia do aluno.

\section{REFERENCIAS}

ALVES, D.; LIMA NASCIMENTO, F.; TEIXEIRA FALCÃO, M.; PESSOA DE LIMA, R. Educação em espaços não formais: química e geografia - da sala de aula para o museu de solos de Roraima. Revista Insignare Scientia - RIS, v. 3, n. 2, p. 237-256, 24 ago. 2020.

ASTOLFI, Jean- Pierre; DEVELAY, Michel. A didática das Ciências. $3^{\circ}$ ed. Campinas, SP: Papirus, 2012.

BACHELARD, G. A formação do espírito científico: contribuição para uma psicanálise do conhecimento. Trad. Estela dos Santos Abreu. Rio de Janeiro: contraponto, 1996.

BATISTA, R. F. M.; SILVA, C. C. A abordagem histórico-investigativa no ensino de Ciências. Estudos Avançados, São Paulo, v.32, n. 94, p. 97-110, set./dez.2018. Disponível em: https://www.scielo.br/scielo.php?script=sci_arttext\&pid=S010340142018000300097. Acesso em: 20 de abr. de 2020.

CARVALHO, A. M. P. O ensino de ciências e a proposição de sequências de ensino Investigativas. In: CARVALHO, A. M. P. (Org.). Ensino de Ciências por Investigação: condições para implementação em sala de aula. São Paulo: Cengage Learning, 2013, p. 1-20.

CARVALHO et al. Ciências no ensino fundamental: o conhecimento físico. São Paulo: Scipione, 2009.

CASTRO, F, R, de. Há sentido na educação não formal na perspectiva da formação integral? Museologia \& Interdisciplinaridade, Brasília, v. 4, n. 8, p.171-184, dez. 2015. Disponível em: 
https://periodicos.unb.br/index.php/museologia/article/view/17166. Acesso em: 23 de abr. de 2020.

COSTA, J. A. O papel da escola na Sociedade actual: implicações no ensino de ciências. Milenium , v.15, p.56-62, jul.1999. Disponível em: https://www.ipv.pt/millenium/15_pers3.htm. Acesso em: 23 de abr. de 2020.

DIAS, C. S. Educação não-formal e emancipação humana sob o olhar da psicologia. Dissertação ( Mestrado em Psicologia) - Centro de Ciências da Vida, Pontifícia Universidade Católica de Campinas, 2007. Disponível em: http://tede.bibliotecadigital.puccampinas.edu.br:8080/jspui/bitstream/tede/202/1/Camila \%20Santos\%20Dias1.pdf. Acesso em: 17 de abr. de 2020.

GOHN, M. G. Educação não-formal, participação da sociedade civil e estruturas colegiadas nas escolas. Ensaio, Rio de Janeiro, v.14, n.50, p. 27-38, jan./mar.2006. Disponível em: https://www.scielo.br/pdf/ensaio/v14n50/30405.pdf. Acesso em: 17 de abr. 2020.

Educação Não Formal, Aprendizagens e Saberes em Processos

Participativos. Investigar em Educação, São Paulo, II a Série, n. 1, p. 35-50, jan. 2014. Disponível em:

http://pages.ie.uminho.pt/inved/index.php/ie/article/view/4/4. Acesso em: 24 abr. 2020.

FREIRE, P. Pedagogia do oprimido. Rio de Janeiro: Paz e Terra, 1987.

HOFMANN, J. Avaliação Mediadora: uma prática em construção da pré-escola à universidade. Porto Alegre: Mediação, 2009.

JÚNIOR, J. M. da S.; COELHO, G. R. A aquisição de conceitos, atitudes e procedimentos de alunos de ensino médio em uma atividade investigativa sobre o tema Efeito Fotoelétrico. In: Encontro Nacional de Pesquisa em Educação em Ciências, X, 2015, Águas de Lindóia/BRA. Anais [...]. São Paulo: ABRAPEC, 2015, p. 1-8.

\section{KRULIK, S; REYS, R. E. A resolução de problemas na matemática escolar. São} Paulo: Atual, 1997.

LOPES, M. R.; SCHEIFELE, A. Estudo de caso clube de ciências: análise das estratégias de inserção dos alunos do ensino fundamental à iniciação científica. In: Os desafios da escola pública paranaense na perspectiva do professor PDE, Cadernos PDE, 2016. Disponível em: http://www.diaadiaeducacao.pr.gov.br/portals/cadernospde/ pdebusca/producoes_pde/2016/2016_artigo_cien_unioeste_marlenedarosalopes.pdf. Acesso em: 20 de abr. de 2020.

LIBÂNEO, J. C. Adeus professor, adeus professora?- novas exigências educacionais e profissão docente. São Paulo: Cortez, 1998.

Pedagogia e pedagogos: inquietações e buscas. Educar, Curitiba, n. 17, p. 153-176, 2001. Disponível em: https://www.scielo.br/pdf/er/n17/n17a12.pdf. Acesso em: 18 de abr. 2020.

Recebido em: 26/05/2020

Aceito em: $23 / 12 / 2020$ 
MARANDINO, M. et al. A educação não formal e a divulgação científica: o que pensa quem faz? In: Encontro Nacional de Pesquisa em Educação em Ciências, IV, Bauru/BRA. Anais [...]. São Paulo: ABRAPEC, 2003, p. 1-13.

MARQUES, J. B. V.; FREITAS, D. Fatores de caracterização da educação não formal: uma revisão da literatura. Educação e Pesquisa, São Paulo, v. 43, n. 4, p. 1087-1110, out./dez. 2017. Disponível em: https://www.scielo.br/pdf/ep/v43n4/1517-9702-epS1517-9702201701151678.pdf . Acesso em: 20 de abr. 2020.

MORIN, E. Os sete saberes necessários à Educação do futuro. São Paulo: Cortez, 2002.

MOURA, E. P. G.; ZUCCHETTI, D. T. Educação além da Escola: acolhida a outros saberes. Cadernos de Pesquisa, São Paulo, v.40, n.140, p. 629-648, maio/ago. 2010. Disponível em: https://www.scielo.br/pdf/cp/v40n140/a1640140.pdf. Acesso em: 24 de abr. de 2020.

ROCHA, C. J. T; MALHEIRO, J. M. da S. Interações dialógicas na experimentação investigativa em um clube de ciências: proposição de instrumento de análise metacognitivo, Amazônia. RECM, Belém, v.14, n. 29, p. 193-207, jan./jun. 2018. Disponível em:

https://periodicos.ufpa.br/index.php/revistaamazonia/article/view/5476/4777. Acesso em: 29 de abr. de 2019.

SASSERON, L. H. O ensino por investigação: pressupostos e práticas. In:

SASSERON, L. H . Fundamentos teórico-metodológicos para o ensino de ciências: a sala de aula, Lic. em ciências, módulo 7. São Paulo: USP/Univesp, 2015, p. 116-124.

SCHIMTZ, V.; TOMIO, D. O Clube de Ciências como prática educativa na escola: uma revisão sistemática acerca da sua identidade educadora. Investigações em Ensino de Ciências, Rio Grande do Sul, v.24, n. 3, p. 305-324, dez. 2019. Disponível em: https://www.if.ufrgs.br/cref/ojs/index.php/ienci/article/view/1539. Acesso em: 17 de abr. de 2020.

SILVA, A. F. de. S.; BASTOS, A. dos S.; SILVA, F. O. Experiências educativas no Centro Juvenil de Ciência e Cultura: um espaço não formal de aprendizagem. Revista Educação e Emancipação, Maranhão, v. 10, n. 2, maio/ago. 2017. Disponível em: http://www.periodicoseletronicos.ufma.br/index.php/reducacaoemancipacao/article/view 17392/4546. Acesso em: 23 de abr. 2020.

ZOMPERO, A. F.; FIGUEIREDO, H. R. S.; GARBIM, T. H. Atividades de investigação e a transferência de significados sobre o tema educação alimentar no ensino fundamental. Ciência \& Educação, São Paulo, v. 23, n. 3, p.659-676, 2017. Disponível em: https://www.scielo.br/scielo.php?pid=S1516-

73132017000300659\&script=sci_abstract\&tlng=pt. Acesso em: 30 de abr. de 2020.

Recebido em: 26/05/2020

Aceito em: $23 / 12 / 2020$ 
